\title{
ESTUDO DA COMPATIBILIDADE DA VIDA ÚTIL DE HABITAÇÕES DO PROGRAMA MINHA CASA MINHA VIDA E A RENDA DOS BENEFICIADOS
}

\author{
$\underline{\text { Leonardo de Brito Cerqueira }}^{1}$; Ana Rita Sulz de Almeida Campos ${ }^{2}$ \\ 1. Bolsista PROBIC/UEFS, Graduando em Engenharia Civil, Universidade Estadual de Feira de Santana, \\ e-mail: leobritocerqueira@gmail.com \\ 2. Professora do Departamento de Letras e Artes, Universidade Estadual de Feira de Santana, \\ e-mail: $\underline{\text { sulz@uefs.br }}$
}

PALAVRAS-CHAVE: vida útil, renda, minha casa minha vida.

\section{INTRODUÇÃO}

Historicamente, o Brasil enfrenta problemas de infraestrutura e habitação decorrentes dos baixos investimentos, da falta de fiscalização por parte dos consumidores, no momento de adquirir imóveis, e por parte dos órgãos competentes além da busca ininterrupta pelo lucro. As classes de baixa renda são, em sua maioria, as mais afetadas pelo déficit habitacional, e por isso, muitas incorporadoras e construtoras tem essas famílias como público alvo de mercado. De acordo com Borges e Sabbatini (2008, p. 02),

Em função deste histórico de baixa qualidade das habitações populares no Brasil, é importante que se discuta, neste momento de crescimento de mercado, qual o desempenho mínimo das novas moradias a serem construídas, até para que sejam evitados os mesmos erros cometidos no passado.

O setor da construção civil viveu um momento de grande expansão, devido ao crescimento econômico do país e a consequente capitalização do setor, através da injeção de recursos pelo governo e com a ampliação de fundos habitacionais como o Sistema Brasileiro de Poupança e Empréstimo (SBPE) e o Fundo de Garantia por Tempo de Serviço (FGTS). Com o objetivo de diminuir o déficit habitacional, o governo brasileiro criou programas como o "Minha casa minha vida" (MCMV) para a construção de casas populares destinadas a vários setores sociais, nesse contexto, o suporte técnico torna-se imprescindível para que essa busca por organização social seja feita com eficiência.

De acordo com notícias divulgadas pelo Portal Brasil, o programa MCMV já beneficiou mais de 10 milhões de pessoas, com a entrega de 2,6 milhões de moradias em todo o país. Grande parte desses beneficiados pertencem a Faixa 1 do programa destinado à famílias com renda mensal de até $\mathrm{R} \$ 1600,00$ e prestações limitadas a 5\% da renda familiar mensal. Para essas famílias foram oferecidos recursos do FAR (Fundo de Arrendamento Social).

Diante desse cenário, entender como as habitações pertencentes ao programa MCMV estão sendo projetadas é uma necessidade, haja vista a compatibilidade da Vida Útil (incluindo durabilidade e manutenibilidade) de tais edificações e a renda das famílias que as adquirem.

\section{MATERIAL E MÉTODOS}

Para o desenvolvimento da pesquisa, inicialmente foi realizado levantamento dos itens relativos à Vida Útil de habitações, incluindo durabilidade e manutenibilidade, previstos através da NBR 15575 "Edificações Habitacionais - Desempenho". Procedemos com a identificação os conjuntos habitacionais pertencentes à faixa 1 do 
Programa Minha Casa Minha Vida (PMCMV) localizadas nas cidades de Feira de Santana, através de consulta à documentação pertinente nos órgãos responsáveis pela execução e acompanhamento do referido programa. Em seguida, selecionamos os conjuntos a serem investigados.

$\mathrm{O}$ acesso aos projetos das edificações selecionadas foi estabelecido junto às empresas que executaram as construções e/ou aos órgãos responsáveis e através de manuais de uso e operação fornecidos pelas construtoras aos proprietários. Paralelamente realizamos pesquisa bibliográfica para dar o suporte teórico e metodológico necessário ao desenvolvimento do trabalho, especialmente os textos científicos que abordavam a temática proposta. De posse dos dados, seguimos a análise da compatibilidade da Vida Útil de habitações pertencentes à primeira faixa do programa Minha Casa Minha Vida e a renda dos seus usuários.

\section{RESULTADOS E/OU DISCUSSÃO}

Nesta sessão estão os resultados encontrados a partir da reflexão da bibliografia que serviu de base para este trabalho, que teve como Objetivo Geral: analisar a compatibilidade da Vida Útil de habitações pertencentes a primeira faixa do programa Minha Casa Minha Vida e a renda dos seus usuários e, como Objetivos Específicos:

- estudar os itens relativos à Vida Útil de habitações incluindo durabilidade e manutenibilidade, previstos na NBR 15575 "Edificações Habitacionais Desempenho";

- conhecer os aspectos relacionados à vida útil de edificações pertencentes a faixa 1 do programa Minha Casa Minha Vida (PMCMV);

- identificar os conjuntos do programa MCMV em Feira de Santana;

- conhecer os projetos dos conjuntos selecionados;

- analisar a viabilidade da manutenção das habitações do programa MCMV em Feira de Santana, de acordo com a renda dos usuários.

Para o levantamento dos dados relativos aos três primeiros objetivos específicos, foi realizada pesquisa documental buscando embasar a pesquisa em normas técnicas e especificações disponibilizadas pelo governo federal, através de portarias publicadas no Diário oficial da União. Além de buscar tais informações junto à Caixa Econômica Federal (CEF).

\section{- Da pesquisa documental}

\section{Processo de Implantação de um Residencial MCMV}

Inicialmente a Caixa Econômica Federal (CEF) contrata a construtora responsável pela execução da obra, então a empresa adquire o terreno onde serão construídas as unidades habitacionais (UH), posteriormente a prefeitura do município fornece o Habite-se (conceito), para, finalmente, as unidades habitacionais serem entregues as famílias sorteadas. Atualmente, o PMCMV está em sua terceira fase e tem passado por mudanças que visam aprimorar o programa.

Os projetos das UH devem atender às especificações dos empreendimentos e da unidade exigidos pela CEF durante a contratação das construtoras. As especificações dos empreendimentos referem-se aos padrões mínimos de desenho urbano, como: mobilidade e acessibilidade, diversidade funcional e espaços livres. As especificações da unidade contemplam os padrões mínimos exigidos para a construção bem como o atendimento à Norma de Desempenho (NBR-15.575/13) (BRASIL, 2016). 
Além do atendimento das especificações exigidas, é importante consultar o caderno de diretrizes que orienta quanto às melhores práticas de projeto (BRASIL, 2016).

\section{Durabilidade e Manutenibilidade}

A importância desses conceitos está na obtenção de melhores resultados relacionados à Vida Útil (VU) do imóvel. Segundo a NBR 15.575/13, para bens duráveis, que possuem alto valor unitário e muitas vezes de aquisição única, como é a habitação, torna-se necessário a imposição, por parte da sociedade, de marcos referenciais para regular o mercado e evitar que o custo inicial prevaleça em detrimento do custo global (ou seja, incluindo o custo com a manutenção e operação ao longo da vida útil) e que uma durabilidade inadequada venha a comprometer o valor do bem e a prejudicar o usuário.

\section{- Da pesquisa empírica \\ Levantamento dos Conjuntos}

Entre os anos de 2009 e 2014 foram construídos cerca de 33 (Trinta e três) empreendimentos no município de Feira de Santana, destinados as famílias com renda de 0 a 3 salários mínimos do Programa Minha Casa Minha Vida (PMCMV). Nesse período 7.480 unidades habitacionais foram construídas seguindo a primeira tipologia de apartamento. Ao todo foram construídas $10.990 \mathrm{UH}$ do PMCMV da primeira e segunda etapa entre os anos de 2009 e 2014, implantados nas chamadas Zonas Especiais de interesse Social (ZEIS).

Para a realização do quarto item dos Objetivos Específicos: "conhecer os projetos dos conjuntos selecionados", foram escolhidos, para o prosseguimento da pesquisa, o residencial "Acquarius" para tipologia "Villages" e os Residenciais "Viver mais Iguatemi I, II e III" para tipologia "Apartamentos". O critério de escolha segue a necessidade de analisar ao menos duas tipologias diferentes.

A partir da seleção, foi estabelecido contato com as empresas para obtenção dos projetos, em especial, os que continham as especificações dos materiais utilizados nas unidades habitacionais. Devido à dificuldade em ter acesso aos projetos, a solução encontrada foi a busca pelo manual do proprietário entregue aos moradores dos residenciais pelas construtoras. Já que, a confecção dos manuais deve seguir a NBR 14037 "Manual de operação, uso e manutenção das edificações", que por sua vez utiliza como referência normativa a NBR 5674 "Manutenção de Edificações". Dessa maneira, o manual contempla parcialmente as informações aqui buscadas, como as relacionadas aos procedimentos recomendáveis para manutenção da edificação, as informações sobre responsabilidades e garantias, e à descrição da edificação como construída.

Para o quinto item dos Objetivos Específicos: "analisar a viabilidade da manutenção das habitações do programa MCMV em Feira de Santana, de acordo com a renda dos usuários", utilizou-se o manual do proprietário contendo as orientações para manutenção preventiva da edificação. A análise visou identificar a viabilidade de tais operações comparando-as com as informações presentes NBR 15.575/13. Apesar dos projetos seguirem especificações diferentes, ou seja, referentes a cada fase do programa MCMV, e, portanto, não estão todas de pleno acordo com a NBR 15.575/13. A Norma de desempenho utilizada para análise da compatibilidade serviu apenas como parâmetro técnico para o desenvolvimento da pesquisa. 


\section{CONSIDERAÇÕES FINAIS}

Para que os projetos das Unidades Habitacionais do Programa Minha Casa Minha Vida sejam aprovados para financiamento eles devem atender às especificações dos empreendimentos e da unidade exigidas pela Caixa Econômica Federal (CEF) durante a contratação das construtoras.

É preciso observar que as habitações subsidiadas pela sociedade e direcionadas à população de baixa renda necessitam de cuidados especiais quando se avalia dois conceitos amplos os de Custo e Benefício. Os materiais utilizados na edificação precisam ser projetados para uma vida útil adequada, necessitando de manutenção preventiva de baixo custo.

Através dos dados coletados junto à CEF constata-se que existe a preocupação em utilizar sistemas construtivos em conformidade, e produzidos por empresas qualificadas pelo Programa Brasileiro de Qualidade e Produtividade do Habitat (PBQP) e seus respectivos Programas Setoriais de Qualidade (PSQ). Tal requisito permite que as edificações pertencentes a Faixa 1 do PMCMV sejam construídas com materiais que apresentem desempenho adequado de acordo com as normas técnicas vigentes e assim diminuam o custo global da unidade residencial, o ideal para os beneficiados de baixa renda.

A análise das orientações das construtoras para manutenção preventiva contidas no Manual do Proprietário mostra que as Unidades Habitacionais são projetadas, em sua maioria, com materiais que necessitem de manutenção com baixo e médio custo, para ambas as tipologias. Ou seja, não possuem sistemas construtivos complexos que exigem alto custo de manutenção e sim sistemas construtivos que atendam minimamente as conformidades normativas técnicas. Logo, os residenciais pertencentes a Faixa 1 do PMCMV são edificações com custo de manutenção adequado a renda dos beneficiados.

O programa MCMV representa para o Brasil um avanço no desenvolvimento social, permite que pessoas que vivem em condições insalubres consigam moradia digna, e, por isso, é ainda mais importante que os órgãos competentes exijam edificações que atendam padrões adequados de desempenho seguindo as normas técnicas, permitindo que as edificações tenham durabilidade adequada e com baixo custo global.

\section{REFERÊNCIAS}

BORGES, C. A. M.; SABBATINI, F. H. O conceito de desempenho de edificações e a sua importância para o setor da construção civil no Brasil. Boletim Técnico da Escola Politécnica da USP, Departamento de Engenharia de Construção Civil, 2008. Disponível em:

«http://www.fau.usp.br/cursos/pos/areas/area_tecnologia/aut5828/bt515_desempenho_edifi cios_borges_sabbatani.pdf». Acesso em jun 2016.

Disponível em: «http://www.minhacasaminhavida.gov.br/habitacao-cidades/programaminha-casa-minha-vida-pmcmv/especificacoes-tecnicas». Acesso em 17 julho 2017

ABNT NBR 15575-1:2013, Edificações habitacionais - Desempenho - Parte 1: Requisitos gerais. 